\title{
ADAPTASI PERILAKU PEDAGANG BAZAR DALAM TERITORI RUANG DAGANG
}

\author{
Estuti Rochimah ${ }^{1,{ }^{*}}$, Handajani Asriningpuri ${ }^{2}$ \\ 1,2 Program Studi Arsitektur, Institut Teknologi Indonesia \\ *estuti@iti.ac.id;
}

\begin{abstract}
ABSTRAK. Bazar telah menjadi daya tarik tersendiri bagi masyarakat Tangerang Selatan, kegiatan ini makin marak berkembang dan dikunjungi masyarakat. Bazar memiliki jadwal hari rutin dengan tempat penyelenggaraan yang berpindah-pindah, antara lain di halaman rumah seseorang, ruang terbuka dalam komplek hunian, penggal jalan lingkungan, depan pertokoan. Uniknya, para pedagang tidak saling berebut area serta mampu melaksanakan kegiatan berdagangnya di lingkungan lokasi dagang berbeda-beda. Para pedagang ini kebanyakan merupakan pedagang kecil dan menjajakan barang dagangannya dengan cara membuat lapak. Penelitian ini bertujuan mengetahui bentuk adaptasi perilaku pedagang pada area dagangnya, sehingga memperkuat terbentuknya teritori ruang dagang bazar. Metode penelitian dilakukan secara deskriptif kualitatif, dengan pengumpulan data melalui observasi dan wawancara. Selanjutnya data diidentifikasi, dikategorikan dan diinterpretasikan untuk menemukankan faktor-faktor, serta keterkaitan antar faktor yang melatarbelakangi adaptasi perilaku hingga terwujudnya teritori ruang dagang bazar tersebut. Hasil penelitian menunjukkan perilaku pedagang; berjalan keliling, duduk di sela-sela barang dagang atau duduk di salah satu sisi tatanan barang yang dijualnya. Bentuk adaptasi tersebut dipengaruhi adanya fleksibilitas perilaku pedagang sebagai upaya adaptasi terhadap ruang dagang yang tersedia, dengan tetap mempertimbangkan kemampuan mengontrol, mengawasi dan berkomunikasi dengan pengunjung, sebagai upaya memperkuat terwujudnya teritori ruang dagang bazar di Tangerang Selatan.
\end{abstract}

Kata kunci: Adaptasi, Pedagang Bazar, Perilaku, Teritori

ABSTRACT. Bazaar has become the main interest for the people of South Tangerang. It is increasingly visited by the people, widespread, and also growing. The bazaar has a regular schedule using moveable stalls; in front of houses, on the open space within the residential area, on the sidewalk, and at the storefront. However, the Sellers are not fighting over the venue and they are able to execute their selling activities in a different location. The sellers are mostly small-scale sellers, and they peddle their wares by making stalls. The study aims to determine the way of adapting behavior from the sellers using moveable stall method. Thus it can strengthen the formation of the bazaar trading space. The research method is descriptive qualitative using observation and interviews. Furthermore, the data were already identified, categorized and interpreted for finding the factors as well as the relationship among the factors behind the establishment of the territory behavioral adaptations to the bazaar trading space. The results showed that the behavior of the sellers was; moving around and sitting in between or aside their selling goods. Those adaption behavior were influenced by their flexibilities in adapting to available stall space with taking into account the ability to control and monitor their stalls as well as communicate with visitors as the effort to strengthen the realization of trading fairs territorial space in South Tangerang.

Keywords: adaptations, behavioral, the sellers of bazaar, territory

\section{PENDAHULUAN}

Kota Tangerang Selatan sebuah kota baru yang sedang tumbuh dan berkembang, beberapa aspek spasial kehidupan masyarakatnya belum terpenuhi dengan baik, salah satunya adalah area dagang sebagai sarana belanja kebutuhan sehari-hari. Hal ini juga menjadi alasan bagi sebagian pedagang untuk melakukan kegiatannya di lain tempat. Mereka membuat kelompok tersendiri dan melakukan kegiatan berdagang secara berpindah tempat pada waktu yang berbeda.
Kegiatan berdagang seperti ini dikenal secara umum dengan sebutan pasar dadakan, pasar kaget, pasar tiban, atau bazar (sebutan masyarakat Tangerang Selatan). Kesemua sebutan tersebut mengarah pada kelompok kegiatan dagang sektor informal.

Kegiatan bazar biasanya diselenggarakan dalam jangka waktu satu minggu sekali, pada sore hingga malam hari, antara pukul 17.00 hingga 22.00 WIB, dan dilakukan di beberapa tempat, antara lain : di halaman rumah seseorang, ruang terbuka dalam komplek 
hunian, penggal jalan lingkungan perumahan, di depan rumah atau deret pertokoan. Lokasi bazar pun berpindah-pindah, sesuai jadwal yang mereka sepakati. Mereka menentukan waktu dan tempat berkegiatan.

Para pedagang ini kebanyakan merupakan pedagang kecil dan menjajakan barang dagangannya dengan cara membuat area sendiri yang dilengkapi dengan meja, tenda, kardus maupun gerobak. Uniknya, mereka bisa tidak saling berebut area dengan pedagang lain sebagai teritori ruang dagangnya. Mereka bisa menyesuaikan diri dalam melakukan kegiatan berdagang di berbagai kondisi lokasi, dan bisa menempati ruang dagang dengan nyaman serta penuh toleransi antar pedagang atas teritori ruang dagangnya. Hal tersebut di atas menimbulkan pertanyaan mengenai bagaimana para pedagang melakukan adaptasi perilaku pada ruang dagang bazar.

Dari uraian inilah maka perlu dilakukan penelitian untuk mengetahui bentuk adaptasi perilaku pedagang informal bazar pada area dagangnya di lokasi yang tersedia, sehingga memperkuat terbentuknya teritori serta mewujudkannya ruang dagang bazar. Selain itu, penelitian ini juga menjadi dasar pengembangan penelitian selanjutnya yang nantinya akan membawa ke pemahaman lebih utuh tentang bazar itu sendiri serta bagaimana bazar seharusnya diakomodir di Kota Tangerang Selatan

\section{ADAPTASI DAN TERITORIALITAS}

Menurut Altman (1975), adaptasi diartikan sebagai perubahan tingkah laku penyesuaian diri agar sesuai dengan lingkungan. Dengan demikian adaptasi perilaku menekankan pada reaksi manusia dalam menghadapi ketidaksesuaian dengan lingkungan.[1] Kata perilaku menunjukan manusia dalam aksinya, berkaitan dengan aktivitas manusia secara fisik, berupa interaksi manusia dengan sesamanya ataupun dengan lingkungan fisiknya (Laurens, 2004).[2]

Haryadi (2011) menyatakan bahwa pendekatan perilaku dalam arsitektur lebih menekankan pada keterkaitan dialektika antara ruang dengan manusia dan masyarakat yang memanfaatkan atau menghuni ruang tersebut. Lebih lanjut dijelaskan oleh Haryadi (2011), bahwa kerangka pendekatan studi perilaku menekankan pada latar belakang manusia seperti: pandangan hidup, kepercayaan yang dianut, nilai-nilai dan norma-norma yang dipegang. [3]

Laurens (2004) memaknai teritori sebagai wilayah yang dianggap menjadi hak seseorang. [2] Sedangkan Haryadi (2011), menjelaskan bahwa teritori adalah suatu area spesifik yang dimiliki dan dipertahankan secara fisik (melalui penandaan) maupun secara non fisik (melalui peraturan atau norma). Teritori ini dikategorikan dalam dua tipe, yaitu teritori obyek dan teritori ide. [3]

Teritori juga diklasifikasikan ke dalam beberapa jenis, yaitu : 1). Teritori primer yang dirasakan tinggi tingkat pengontrolannya, merupakan tempat yang sangat pribadi, akrab, harus dengan izin khusus, dan pengendaliannya relatif tetap; 2). Teritori sekunder yang dirasakan sedang tingkat pengontrolannya, merupakan tempat yang dikuasai oleh sejumlah orang, pengendaliannya seperti teritori primer, dan penggunanya bisa berganti; 3). Teritori publik yang rendah tingkat pengontrolannya, pada prinsipnya semua orang diperkenankan berada di tempat tersebut (Laurens 2004). [2]

Sedangkan, teritorialitas menurut Laurens (2004), merupakan sebuah perwujudan ego yang menandakan seseorang tidak ingin diganggu. Lebih lanjut dijelaskan bahwa teritorialitas adalah sesuatu yang berkaitan dengan ruang fisik, tanda, kepemilikan, pertahanan, personalitas dan identitas, Termasuk di dalamnya ada dominasi, kontrol, konflik keamanan, gugatan akan sesuatu dan pertahanan. Teritorialitas berfungsi sebagai suatu proses yang terpusat dalam personalisasi, agresi, dominasi, memenangkan, koordinasi, dan kontrol, juga memiliki hirarki baik dalam berbagai skala peruangan. [2]

Ruang, merupakan wadah suatu aktivitas terjadi. Ruang tidak sekadar perwujudan fisik semata, tetapi juga merupakan perwujudan aktivitas yang ada di dalamnya. Ruang merupakan suatu wadah yang tidak nyata akan tetapi dapat dirasakan oleh manusia (Karlen, 2008).[4]

Adapun hubungan manusia dengan ruang lingkungan dapat dibagi menjadi 2 macam (Hariyono, 2007), yaitu:

- Hubungan dimensional adalah ruang terkait dengan dimensi-dimensi yang 
berhubungan dengan tubuh manusia dan pergerakannya untuk kegiatan manusia.

- Hubungan psikologi yaitu menentukan ukuran-ukuran kebutuhan ruang untuk kegiatan manusia, yang terkait dengan persepsi manusia terhadap ruang lingkungannya.

Lebih lanjut dijelaskan bahwa dalam hubungan manusia dan ruang, salah satu perasaan manusia yang penting mengenai ruang ialah perasaan teritorial. Perasaan ini untuk memenuhi kebutuhan dasar akan identitas diri, kenyamanan dan rasa aman pada pribadi manusia. [5]

Menurut Manning, (1991) dalam Hariyono (2007), sektor informal biasanya digunakan untuk menunjukkan sejumlah kegiatan ekonomi yang berskala kecil. Lebih lanjut Hariyono (2007) menyebutkan ciri sektor informal, sebagai berikut: modal dan omzetnya kecil, dilakukan atas dasar hitungan harian; peralatan yang digunakan sederhana; tidak mempunyai tempat tetap serta mudah berpindah; umumnya melayani golongan masyarakat yang berpenghasilan rendah; relatif tidak membutuhkan ketrampilan khusus; lebih bertujuan mencari lapangan pekerjaan dari pada untuk mencari keuntungan.[5]. Dengan demikian dapat dikatakan bahwa perilaku seseorang merupakan bentuk aktualisasi eksistensi kepemilikan teritori ruang yang menjadi bagian dari lingkungannya.

\section{METODE PENELITIAN}

Penelitian ini dilakukan secara deskriptif kualitatif, dengan melihat dan memahami berbagai hal terkait dengan dinamika masyarakat dalam upaya meruang (Groat, 2002) [6], yaitu meruang di bazar. Data diperoleh melalui observasi dan wawancara terstruktur. Sedangkan analisis dilakukan melalui identifikasi, klasifikasi temuan hasil observasi maupun wawancara.

Penelitian ini dilakukan di beberapa tempat bazar yang berada wilayah Tangerang Selatan, Banten, yaitu:

1. Kompleks Pemukiman Puri Serpong, Setu, Tangerang Selatan

2. Penggal jalan Hutama Karya Kalurahan Kademangan Setu, Tangerang Selatan

3. Jalan Arya Putra Kedaung Ciputat, Tangerang Selatan.

4. Jalan Pendidikan Ciputat, Tangerang Selatan

5. Lapangan Sepak Bola Sudimara Jombang, Tangerang Selatan
Pemilihan lokasi atau penentuan sampel tersebut dilakukan secara purposive sampling yaitu dipilih dengan pertimbangan dan tujuan tertentu (Moleong, 2002), [7] dengan berdasar pada hasil pengamatan awal serta kemudahan akses baik informasi maupun lokasi. Selanjutnya sampel dalam penelitian ini disebut sebagai kasus.

\section{HASIL DAN PEMBAHASAN}

Pemilihan lokasi bazar lebih banyak dipengaruhi oleh keyakinan pengelola maupun pedagang akan potensi lokasi yang strategis mudah didatangi pengunjung. seperti pada Gambar 1 berikut ini .
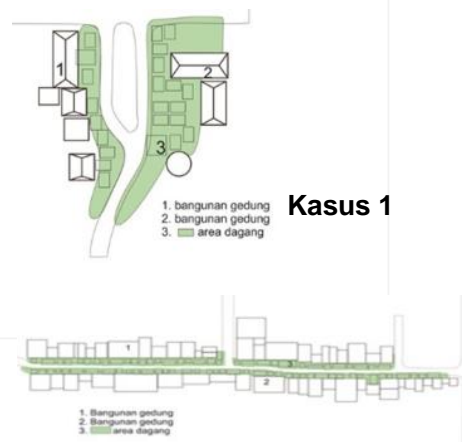

Kasus 2
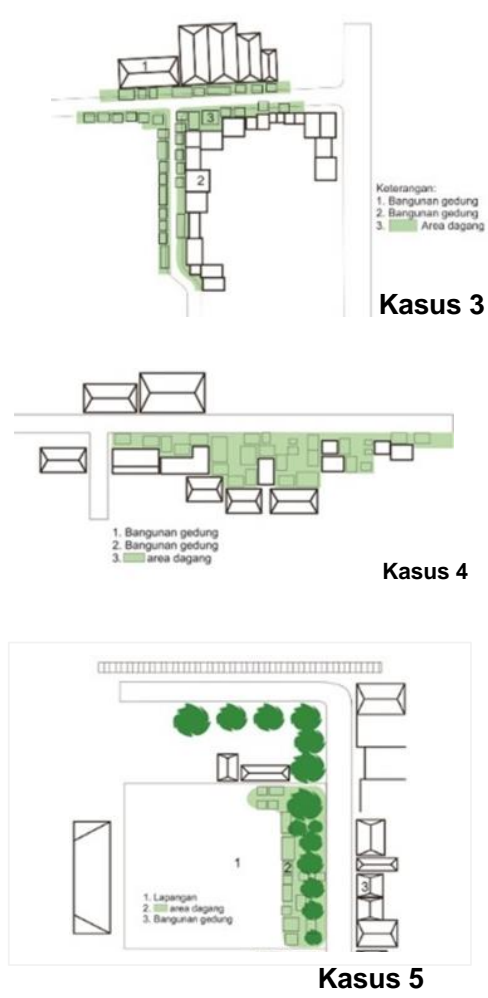

Gambar 1. Lokasi dan bentuk ruang bazar (Sumber: Hasil Survei, 2016) 
Adapun penggagas penentu lokasi tidak selalu dilakukan oleh pengelola bazar, melainkan ada juga yang berasal dari usulan pengelola kawasan permukiman atau aparat setempat. Berdasarkan potensi strategis serta ketersediaan lahan, maka lokasi-lokasi yang dirasa sesuai untuk dijadikan tempat kegiatan bazar yaitu: di salah satu sisi atau dua sisi penggal jalan, di halaman dan di lapangan. Lokasi bazar ini berpengaruh pada jenis, bentuk ruang, serta tatanan ruang dagangnya. Adapun tatanan ruang dagang tercipta, antara lain: memanjang di kedua sisi mengikuti bentuk penggal jalan, gabungan memanjang dengan berkelompok di sela-sela bangunan, memanjang berlapis menyesuaikan keadaan lahan seperti gambar 1 di atas..
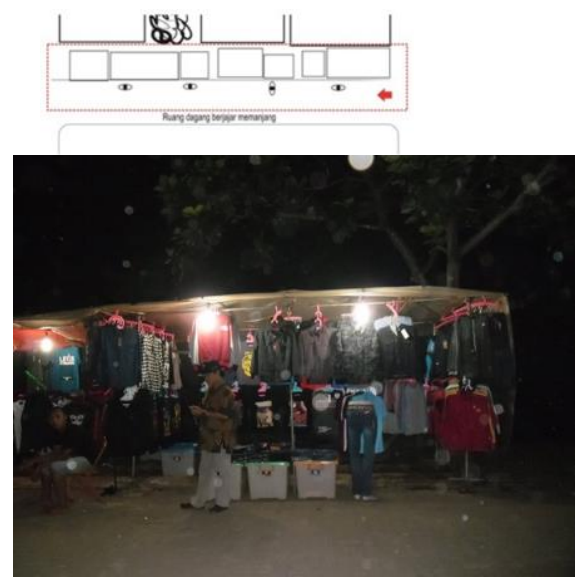

Gambar 2. Ruang dagang berjajar memanjang (Sumber: Dokumentasi Pribadi, 2016)

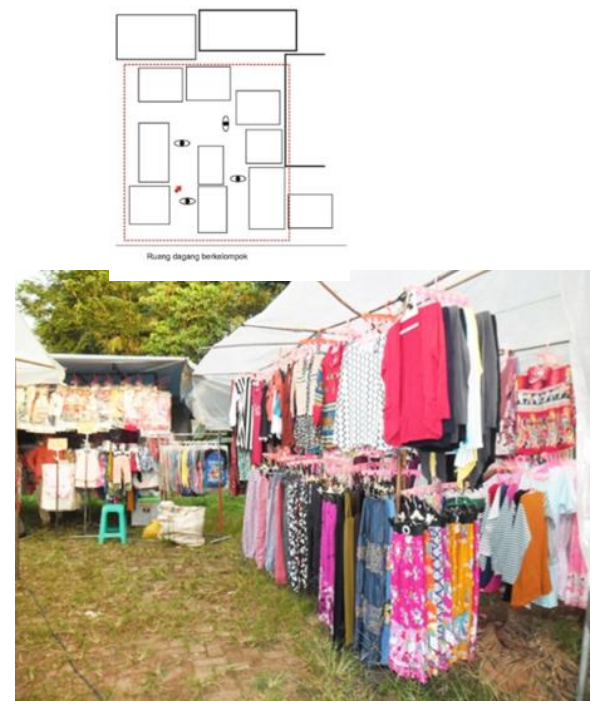

Gambar 3. Ruang dagang mengelompok (Sumber: Dokumentasi Pribadi, 2016)
Tatanan ruang dagang seperti di atas, tentu berpengaruh pada kurangnya kenyamanan, keamanan bahkan menambah kemacetan lalu lintas di sekitar lokasi bazar. Guna mengurangi kemacetan tersebut, ada beberapa orang yang terlibat mengatur keamanan maupun kenyamanan lingkungan.

Jenis komoditas dagangan yang beragam tidak berpengaruh terhadap penentuan area berdagang di bazar. Para pedagang mendapatkan area dagang berdasarkan ketersediaan ruang serta kompromi dan kesepakatan dengan pengelola. Adapun antar pedagang sendiri, mereka saling menghargai akan penempatan tersebut. Bahkan saling peduli terhadap area yang sudah biasa ditempati pedagang sebelumnya. Komunikasi, peduli serta saling menghargai karena kemiripan tujuan berdagang ini, memperkuat adanya perwujudan teritori ruang dagang antar sesama pedagang, meskipun jenis barang dagangannya berbeda.

Wujud unit area ruang dagang dari jenis komoditas dagang yang beragam, diidentifikasi menurut cara menampilkan barang dagang, antara lain: menggelar dagangan di atas permukaan lantai, meletakkan di atas papan, menggunakan rak plastik, menggantungkan pada manekin, dengan gerobak maupun di atas kendaraan (Gambar 4 ).
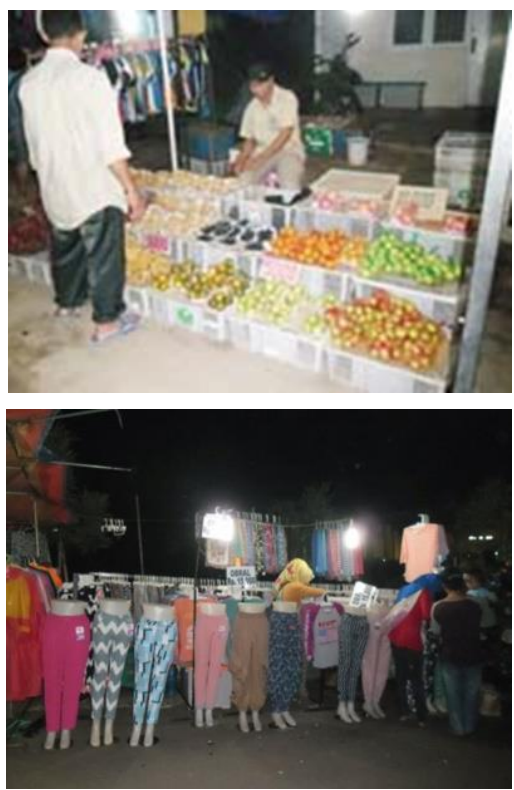

Gambar 4. Berbagai cara memajang dagangan (Sumber: Dokumentasi Pribadi, 2016) 
Cara tersebut akan memudahkan pedagang untuk memperkenalkan barang dagangan serta mengidentifikasi kepemilikan barang dagangan maupun area ruang dagang itu sendiri. Berbagai jenis barang komoditas dijual di bazar, antara lain: perlengkapan rumah tangga, pakaian, makanan, kebutuhan sekolah hingga kebutuhan tersier (compact disc, asesoris pakaian, mainan.

Aktivitas bazar berlangsung dari seputar pukul 17.00 hingga 22.00 WIB. Para pedagang biasanya mulai berdatangan sekitar pukul 16.00 WIB. Dilihat dari logat bahasa pedagang, mereka berasal dari berbagai suku dan daerah. Namun mereka telah lama tinggal dan menetap di sekitar Kota Tangerang Selatan. Para pedagang menuju tempat bazar dengan menggunakan kendaraan pribadi (motor, mobil), kendaraan umum (angkot, ojek), ada pula yang berjalan kaki.

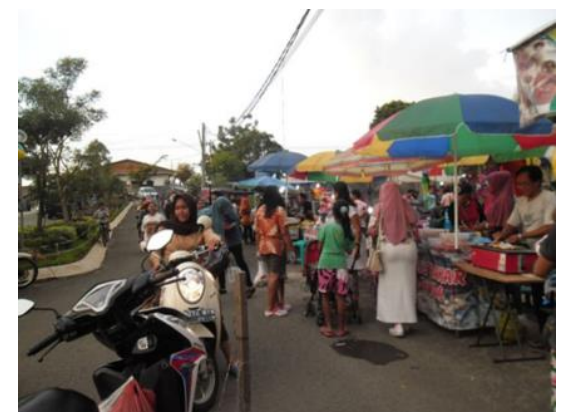

Gambar 5. Sarana parkir dekat area dagang (Sumber: Dokumentasi Pribadi, 2016)

Cara kedatangan ini memiliki konsekuensi perlu disediakan tempat parkir. Para pengelola memahami konsekuensi tersebut. Hal ini terlihat adanya sarana parkir sederhana yang dibuat dengan pembatas rafia (Gambar 5), disediakan oleh pengelola atau masyarakat setempat.

Saat melakukan aktivitas berdagang, para pedagang ini terlihat santai tidak tergesa-gesa dalam melayani pengunjung, tidak bersikeras memaksa pengunjung untuk membeli barang dagangannya. Kondisi ini menjadikan suasana bazar cenderung lebih sebagai arena rekreasi. Baik pengunjung maupun pedagang terlihat ramah dan akrab dalam menawarkan maupun membeli barang dagangan.

Berbagai aktivitas yang dilakukan oleh para pedagang cenderung lebih mengutamakan rasa memiliki dan upaya kontrol terhadap penggunaan area dagangnya. Pengertian kontrol diartikan sebagai mekanisme mengatur batas antara pedagang yang satu dengan lainnya untuk memperjelas batas-batas kepemilikan, pertahanan ataupun penggunaan secara khusus atas ruang tersebut.

Secara konkrit pernyataan kepemilikan tersebut ditandai dengan menggunakan bentuk elemen fisik yang menyatakan suatu tempat ditempati, seperti: adanya tikar, tenda, gerobak, payung, bangku, ember maupun perbedaan permukaan lantai. Sedangkan secara abstrak, pernyataan kepemilikan serta kontrol terhadap area dagang dapat dilihat melalui berbagai aktivitas yang dilakukan pedagang dengan hasil kegiatannya, seperti berjalan mondar-mandir di seputar area dagangnya, atau duduk di dekat barang dagangan. Pernyataan kepemilikan terhadap suatu ruang seperti di atas, sesuai dengan pendapat Laurens (2004)[1], bahwa suatu ruang bisa ditandai kepemilikannya secara konkrit (bentuk fisik) atau simbolik (non fisik). (Gambar 6).

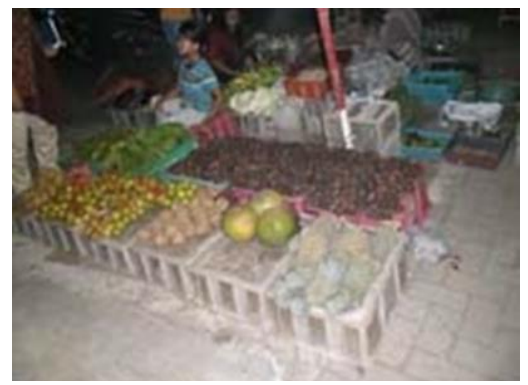

Gambar 6. Area dagang dibatasi secara fisik menggunakan kotak plastik

(Sumber: Dokumentasi Pribadi, 2016)

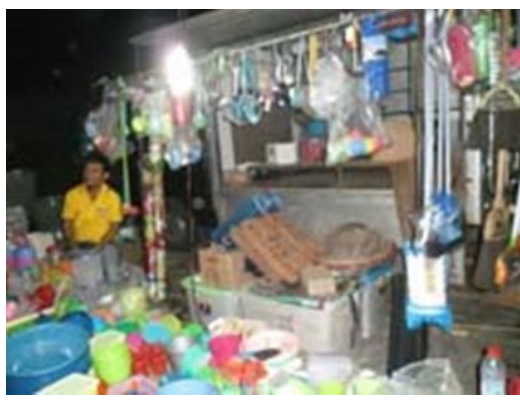

Gambar 7. Wujud ruang dagang temporer mudah bongkar pasang

(Sumber: Dokumentasi Pribadi, 2016)

Wujud ruang dagang yang dibuat atau didirikan oleh para pedagang bersifat temporer dengan material mudah dibongkar pasang, dan sekilas tampaknya rentan terhadap intervensi tingkah laku dari pengunjung. Namun ternyata wujud tersebut justru memudahkan interaksi dan komunikasi antara pembeli dengan pengunjung (Gambar 7). 
Dalam melakukan aktivitas berdagang, semua pedagang berupaya menata barang dagangannya berdasar jenis barang serta tuntutan kemudahan pedagang berinteraksi dengan pengunjung melihat barang tersebut (Gambar 8).

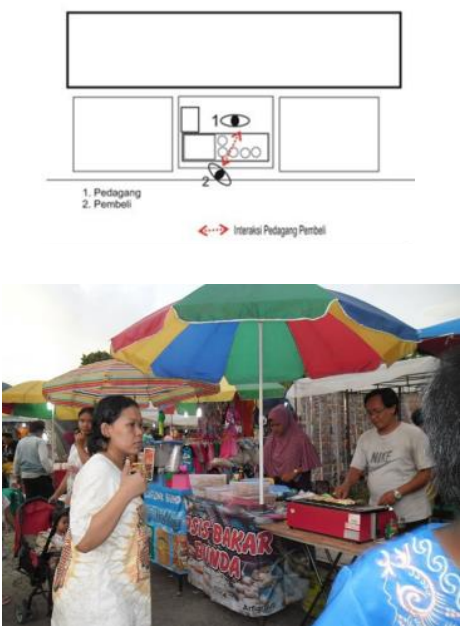

Gambar 8. Interaksi pedagang pembeli (Sumber: Dokumentasi Pribadi, 2016)

Kedua hal tersebut diakomodir pedagang dengan cara mewujudkan area ruang dagangnya, sedemikian rupa sehingga komunikasi antara pedagang serta pengunjung lebih efektif dan persuasif agar barang dagangnya laku terjual. Ruang-ruang tersebut seperti pada Gambar 9, bahwa aktivitas pedagang dan pengunjung berbaur terjadi dalam satu ruang yang sangat dekat dengan barang dagangan yang dijualnya

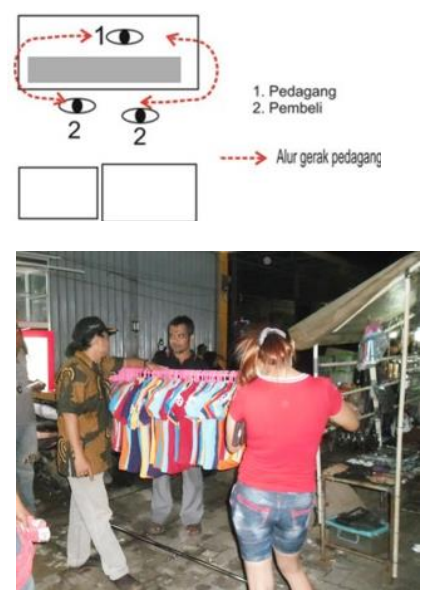

Gambar 9. Pedagang membaur dengan pembeli (Sumber: Dokumentasi Pribadi, 2016)

Hampir tidak ada batas pembeda atau pemisah ruang aktivitas untuk pedagang maupun pengunjung. Baik pedagang maupun pengunjung bebas leluasa mengelilingi barang dagangan yang dipajang atau disajikan. Bahkan ada beberapa pedagang pakaian selalu berjalan mondar-mandir memutari seluruh barang dagangannya. Aktivitas pedagang yang mondar-mandir berkeliling area dagang ini memberikan isyarat pada pengunjung bahwa pedagang tersebut adalah pemilik area serta barang dagangan tersebut. (Gambar 10)
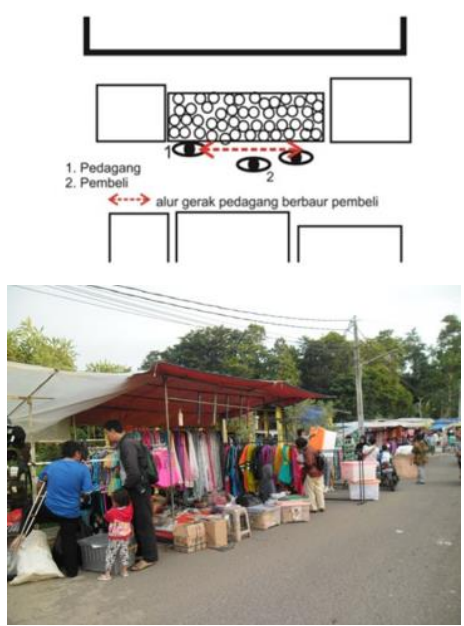

Gambar 10. Pedagang mondar-mandir bersama pembeli

(Sumber: Dokumentasi Pribadi, 2016)

Demikian pula dengan beberapa pedagang yang makanan siap santap. Meskipun mereka menjajakan makanan dengan perlengkapan meja ataupun gerobak, para pedagang ini tidak tinggal diam berdiri hanya di satu tempat. Mereka juga berjalan dari satu sisi ke sisi yang lain untuk lebih mendekatkan diri kepada pengunjung. Perilaku pedagang seperti itu ternyata mampu memperjelas kepada pengunjung akan perannya selaku pedagang sekaligus pemilikan area tersebut.
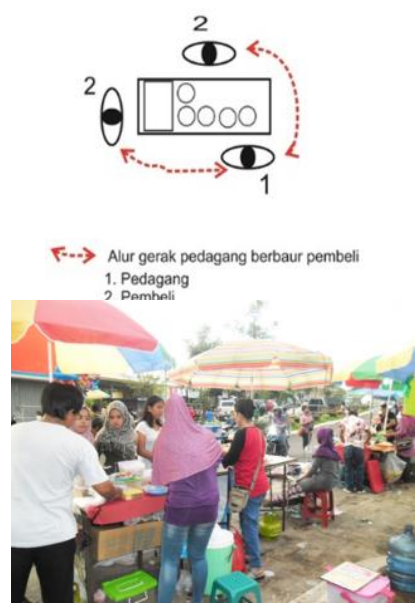

Gambar 11. Pedagang bergerak mengelilingi meja dagang

(Sumber: Dokumentasi Pribadi, 2016) 
Pada Gambar 11 di atas, garis putus-putus menggambarkan gerak fisik sering dilakukan oleh pedagang. Dapat kita lihat bahwa gerak fisik tersebut hanya menjangkau area ruang dagang masing - masing pedagang. Hal Ini menandakan bahwa kegiatan pedagang cukup sebatas menjaga dan mengawasi barang dagangan serta melayani pengunjung.

Terkait dengan tuntutan kemudahan pengawasan serta pelayanan kepada pengunjung, ada beberapa pedagang yang memisahkan antara ruang aktivitas pedagang dan ruang pengunjung (Gambar 12). Selain itu, pemisahan ruang aktivitas tersebut juga dipengaruhi oleh jenis komoditas barang dagang, seperti: pedagang kopiah, alat rumah tangga, dan sayuran. Terpisahnya ruang aktivitas antara pedagang dengan pengunjung mampu memberikan rasa lebih aman bagi pedagang serta mempermudah memamerkan dagangannya
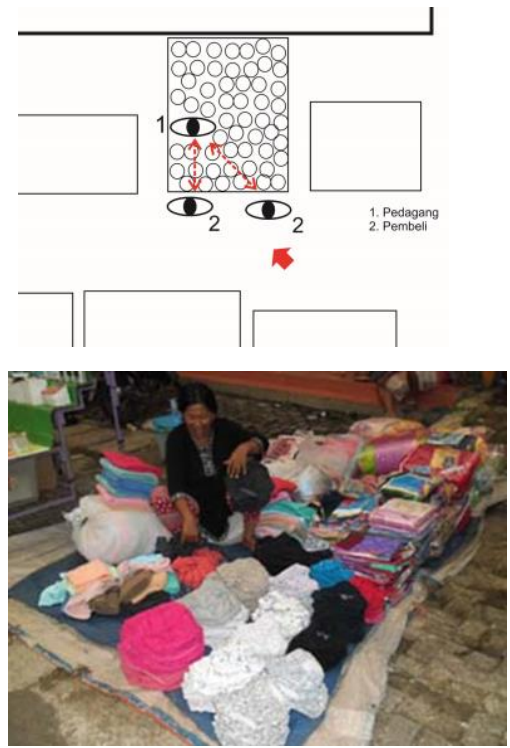

Gambar 12. Ruang pedagang dan pembeli terpisah oleh tatanan dagangan

(Sumber: Dokumentasi Pribadi, 2016)

Aktivitas atau perilaku yang berlangsung seperti di atas, dapat membangkitkan dan tumbuhnya rasa memiliki terhadap area ruang dagang tersebut. Perilaku yang demikian akan berpengaruh terhadap kualitas hubungan antar individu/kelompok dengan teritori ruang dagangnya.

Berdasar tuntutan dan kebutuhan memajang, mengawasi, mengontrol terhadap barang dagangan, serta tuntutan interaksi antara pedagang dengan pembeli, maka pedagang berupaya menyesuaikan perilakunya dengan cara melakukan tindakan, antara lain: duduk di depan hamparan/deretan barang dagangan, duduk di antara hamparan/deretan barang dagangan, berdiri di salah satu sisi meja/gerobak dagangan, serta berdiri sambil berjalan mengelilingi barang dagangan. Tindakan-tindakan tersebut mampu memberikan isyarat kepemilikan area dagangnya sebagai teritori ruang dagang di bazar.

\section{KESIMPULAN}

Dari bahasan di atas, ditemukan adanya fleksibilitas perilaku pedagang sebagai upaya beradaptasi terhadap ruang dagang bazar yang tersedia, dengan tetap mempertimbangkan kemampuan mengontrol, mengawasi dan berkomunikasi dengan pengunjung.

Bentuk adaptasi tersebut, yaitu: duduk di depan atau di antara hamparan/deretan barang dagangan; berdiri di salah satu sisi meja/gerobak dagangan, serta berdiri sambil berjalan mengelilingi barang dagangan.

Perilaku tersebut didasarkan pada rasa saling menghargai, peduli dan kesamaan tujuan berdagang. Hal ini memperkuat adanya perwujudan teritori ruang dagang antar sesama pedagang, meskipun jenis barang dagangannya berbeda.

\section{UCAPAN TERIMA KASIH}

Ucapan terimakasih disampaikan kepada Kemenristekdikti yang telah mendanai penelitian ini melalui LP3M - ITI dengan No. Kontrak : 807/K3/KM/SPK.LT/2016.

\section{DAFTAR REFERENSI}

[1] Altman, I, (1975), The Environment and Social Behavior. California; Books/Cole Publishing Company

[2] Laurens, JM. (2004), Arsitektur dan Perilaku Manusia, Jakarta; PT. Grasindo

[3] Haryadi dan Setiawan, Bakti, (2011), Arsitektur Lingkungan dan Perilaku, Yogyakarta; Gadjah Mada University Press

[4] Karlen, Mark, (2008), Dasar-Dasar Perencanaan Ruang, Jakarta; Erlangga

[5] Hariyono, Paulus, (2007), Sosiologi Kota untuk Arsitek, Jakarta; Bina Aksara

[6] Groat, L., Wang, D. (2002). Architectural Research Methods. New York: John Wiley \& Sons. Inc. 
[7] Moleong, Lexy, (2002), Metodologi Penelitian Kualitatif, Jakarta; Rosda Karya, 